Dhaka Univ. J. Sci. 65(1) 49-54, 2017 (January)

\title{
Comparative Study for Photodegradation of Remazol Red R by Different $\mathrm{TiO}_{2}$ Samples
}

\author{
Nurnabi Rashed, A.Z.M. Mainul Islam Mazumder and Md. Mufazzal Hossain*
}

Department of Chemistry, Dhaka University, Dhaka-1000, Bangladesh

(Received: 25 April 2016; Accepted: 1 January 2017)

\begin{abstract}
Potassium dichromate modified $\mathrm{TiO}_{2}$ photocatalyst $\left(\mathrm{MD}-\mathrm{TiO}_{2}\right)$ was prepared and its photocatalytic activity was compared with that of ordinary commercial $\mathrm{TiO}_{2}\left(\mathrm{C}-\mathrm{TiO}_{2}\right)$ and special Degussa $\mathrm{P} 25 \mathrm{TiO}_{2}\left(\mathrm{D}-\mathrm{TiO}_{2}\right)$. An organic dye, remozol red R(RRR) was used as a substrate for photodegradation from aqueous solution into environmentally safe products such as water, carbon dioxide and mineral ions. The photodegradation of RRR was carried out by varying the concentration of different types of $\mathrm{TiO}_{2}$ suspension, initial concentrations of dyes between $0.5 \times 10^{-4} \mathrm{M}$ and $2.5 \times 10^{-4} \mathrm{M}$, pH between 2.0 and 6.0 and light sources which are UV, artificial visible and sunlight. With increasing the catalyst concentration, percent degradation was found to increase up to a concentration of $1.2 \mathrm{~g} / 100 \mathrm{~mL} \mathrm{of} \mathrm{C}-\mathrm{TiO}_{2}, 0.12 \mathrm{~g} /$ $100 \mathrm{~mL}$ of $\mathrm{D}-\mathrm{TiO}_{2}$ and $0.10 \mathrm{~g} / 100 \mathrm{~mL}$ of modified $\mathrm{MD}^{-\mathrm{TiO}_{2}}$ for a definite concentration of RRR. However, RRR shows adsorption on TiO samples except $\mathrm{C}-\mathrm{TiO}_{2}$. Again, the photodegradation efficiency is inversely affected by the dye concentration. Thus, the removal efficiency was found to be influenced by all of the above parameters. The maximum removal efficiency is found at $\mathrm{pH} 3.0 \mathrm{under}$ sunlight in the presence of modified $\mathrm{MD}-\mathrm{TiO}_{2}$, which suggests that $\mathrm{MD}^{-\mathrm{TiO}_{2}}$ can be used as an effective material for the removal of RRR instead of C-TiO and $\mathrm{D}-\mathrm{TiO}_{2}$.
\end{abstract}

\section{Introduction}

Textile and leather industries are discharging effluents containing a large volume of carcinogenic and nonbiodegradable dyes directly into waterstreams ${ }^{1}$. The azo dyes constitute the largest and the most important class of commercial dyes ${ }^{2,3}$. Azo dyes typically contain the chromophoric $-\mathrm{N}=\mathrm{N}$ - group unit in their molecular structures ${ }^{4}$. Usually azo dyes are non-degradable under sunlight and their stability is proportional to their structural complexity $^{4,5}$. These non-degradable azo dyes are mainly present in textile wastewater exhaust. Remazol red $\mathrm{R}$ (RRR), (Fig. 1) is an important azo dye which is commonly used in textile industries and mixed with the wastewater during dyeing process.

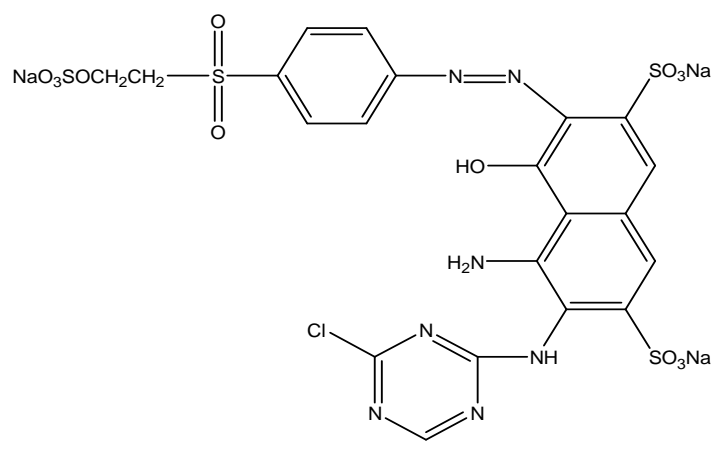

Fig. 1. Molecular structure of Remazol Red R (RRR)

For the treatment of wastewater from textile dyeing industries, various physical and chemical methods have been developed. Physical method such as adsorption using activated carbon is very efficient in removing organic pollutants including dyes. However reactivation of the adsorbent forreuse is not economically favourable in large scale applications. Membrane filtration techniques have the potential to produce reusable water and to remove the dyes completely. But all physical methods terminate in secondary waste generation ${ }^{6}$. Chemical degradation processes like ozonation, sodium hypochloride treatment and electrochemical destruction are used for the decolorization of some classes of dyes ${ }^{7}$. But ozonation needs on-site preparation of ozone. Hypochlorite treatment leaves water with high chloride content and electrochemical destruction requires very high power supply which is not economically feasible ${ }^{8}$.

In recent years, semiconductor oxide mediated photodegradation of textile dyes are drawing attention of the scientists all over the world. Titanium dioxide represents one of the most efficient photocatalyst ${ }^{9-13}$, although the effective photo-excitation of $\mathrm{TiO}_{2}$ semiconductor particles requires the application of light with energy higher than their band gap energy $(3.2 \mathrm{eV})$. This is an advanced oxidation process based on the generation of reactive species such as hydroxyl radicals that oxidizes the organic dyes quickly and nonselectively ${ }^{14,15}$. Photosensitization of titanium dioxide involving doping or surface modification with p-block elements $(\mathrm{N}, \mathrm{C}, \mathrm{S}, \mathrm{Cl}, \mathrm{Br}, \mathrm{I}, \mathrm{Pb})^{16-25}$ and with d-block elements $(\mathrm{V}, \mathrm{Cr}, \mathrm{Au}, \mathrm{Rh}, \mathrm{Ni}, \mathrm{Pt})^{26-30}$ are well studied in very recent years. In this work, we have attempted to prepare $\mathrm{Cr}_{2} \mathrm{O}_{7}{ }^{2-}$ ion modified Degussa P25 $\mathrm{TiO}_{2}\left(\mathrm{MD}-\mathrm{TiO}_{2}\right)$ and we have applied it as a photocatalyst for photodegradation of RRR dye. A comparative study of photodegradation of RRR dye by different $\mathrm{TiO}_{2}$ samples, which are $\mathrm{MD}-\mathrm{TiO}_{2}$, ordinary commercial $\mathrm{TiO}_{2} \quad\left(\mathrm{C}-\mathrm{TiO}_{2}\right)$ and unmodified Degussa P25 $\mathrm{TiO}_{2}\left(\mathrm{D}-\mathrm{TiO}_{2}\right)$, has been discussed.

\section{Experimental}

Three different types of $\mathrm{TiO}_{2}$ which are $\mathrm{C}-\mathrm{TiO}_{2}, \mathrm{D}-\mathrm{TiO}_{2}$ and MD- $\mathrm{TiO}_{2}$ were used as photocatalysts. C-TiO ${ }_{2}$ and $\mathrm{D}-\mathrm{TiO}_{2}$ were obtained from Fluka, Switzerland and $\mathrm{MD}-\mathrm{TiO}_{2}$ was prepared by modifying $\mathrm{D}-\mathrm{TiO}_{2}$ with $\mathrm{K}_{2} \mathrm{Cr}_{2} \mathrm{O}_{7}$. Double distilled water was used throughout the present study.

The surface modified material was obtained from $\mathrm{D}-\mathrm{TiO}_{2}$ by 4 hours sonication with aqueous solution of $\mathrm{K}_{2} \mathrm{Cr}_{2} \mathrm{O}_{7}$ at room temperature. Where $\mathrm{Cr}_{2} \mathrm{O}_{7}{ }^{2-}$ were at the titanium dioxide surface from acidic solution. Modification of white D- $\mathrm{TiO}_{2}$ resulted into light yellow $\mathrm{MD}-\mathrm{TiO}_{2}$ photocatalyst ${ }^{31}$.

All the aqueous solutions were prepared with deionized water. The $\mathrm{C}-\mathrm{TiO}_{2}, \mathrm{D}-\mathrm{TiO}_{2}$ and $\mathrm{MD}-\mathrm{TiO}_{2}$ suspensions were prepared separately by taking the required amount of $\mathrm{TiO}_{2}$ in a beaker. Exactly $20 \mathrm{~mL}$ deionized water was added to it. The $\mathrm{TiO}_{2}$ was soaked overnight to achieve the smoothness

*Author for correspondence. e-mail: mufazzal@du.ac.bd 
of the surface. This suspension was then used for either adsorption or photodegradation study.

The dye, RRR was obtained from Dyester (Germany) and used here without further purification. 10 well stoppered reagent bottles each of which contains $1.0 \times 10^{-4} \mathrm{M}$ dye solution in $100 \mathrm{~mL}$ suspension containing $0.10 \mathrm{~g}$ of $\mathrm{TiO}_{2}$ were taken. Then the reagent bottles were placed in a thermostatic shaker maintained at $30{ }^{\circ} \mathrm{C}$ temperature and shacked continuously. The reagent bottles were successively withdrawn after 10,20,30, 50, 70 and 90 minutes. $5 \mathrm{~mL}$ of supernatant liquid from each bottle was centrifuged. The absorbance of the clear solutionwas measured using UVvisible spectrophotometer (UV-1610A, Shimadzu, Japan) at $\lambda_{\max }=520 \mathrm{~nm}$ of the aqueous dye solution and the concentrations of the RRR solutions were calculated. The initial concentration in the absence of $\mathrm{TiO}_{2}$ was determined. The time taken for centrifuge and subsequent analysis was kept constant. Similar procedure was followed for other RRR solution of concentrations $0.5 \times 10^{-4} \mathrm{M}, 1.5 \times 10^{-4} \mathrm{M}$, $2.0 \times 10^{-4} \mathrm{M}$ and $2.5 \times 10^{-4} \mathrm{M}$.

A beaker of $100 \mathrm{~mL}$ was taken as the reactor to perform photodegradation of RRR in the presence of different forms of $\mathrm{TiO}_{2}$. The source of radiation was comprised of a lamp emitting monochromatic radiation of $254 \mathrm{~nm}$. The reactor was placed on a magnetically stirred plate and the distance of the solution surface from the lower part of the lamp was fixed at $5.0 \mathrm{~cm}$. The total system was enclosed in a wooden box called lamp house. Inner surfaces of the lamp house were covered with aluminium foil. To study the photodegradation of RRR molecules, a solution of $1.0 \times 10^{-4}$ $\mathrm{M}$ in $100 \mathrm{~mL}$ suspension containing $0.10 \mathrm{~g}$ of $\mathrm{TiO}_{2}$ was taken in the beaker. A magnetic bar was placed to the reaction mixture. Then the solution was irradiated with constant stirring (magnetically) and the degradation time was monitored using a stopwatch. After a definite interval of time certain portion of the irradiated solution was taken out and then the absorbance of the irradiated solution was measured.

The percent degradation (\%) has been calculated as-

$\%$ photodegradation $=\frac{\left(A_{0}-A_{t}\right) 100}{A_{0}}$

Where, $\mathrm{A}_{0}$ is the absorbance at $\mathrm{t}=0$ and $\mathrm{A}_{\mathrm{t}}$ is absorbance at time $\mathrm{t}$.

This experiment was repeated to study the effect of catalyst dosage, effect of initial concentration of RRR, effect of $\mathrm{pH}$ and effect of light source on photodegradation of RRR.

$\mathrm{X}$-ray diffraction (XRD) data of $\mathrm{MD}-\mathrm{TiO}_{2}$ were recorded (Philips PW-1380 X-ray generator operating at $40 \mathrm{kV}-30$ $\mathrm{mA}$ ) on image plate using an XDC-700 Guinier-Hägg focusing camera. The radiation used was $\mathrm{Cu} K \alpha 1$ and the sample was exposed for 15 minutes. The image plate was then scanned using HD-CR 35 NDT/ CR 35 NDT scanner. The recorded X-ray data were plotted as Intensity vs. $2 \theta$

\section{Results and Discussion}

Spectral changes of the dye during photodegradation

RRR is a strongly absorbing dye in the UV-visible region with distinct bands at $290 \mathrm{~nm}$ and in the visible region at $520 \mathrm{~nm}$. The latter band is responsible for the colour arising from aromatic rings connected by azo groups and the former is associated with benzene like structures in the molecule. Fig. 2 shows time dependent absorption spectra of RRR. The topmost spectrum is the original spectrum of the aqueous solution of $1.0 \times 10^{-4} \mathrm{M}$ dye and the next one is for the same solution after adsorption leading to the equilibrium. All other subsequent spectra were recorded during photodegradation at different time intervals. It is clear from the figure that the intensities of both the peaks decrease during adsorption. However, the intensities of both the peaks decreased sharply during photodegradation and this peak almost disappeared after 90 minutes of photodegradation. The disappearance of the peak at $520 \mathrm{~nm}$ is related to the removal of the azo group leading to the decolourisation of the dye. However, decrease in the intensity near $200 \mathrm{~nm}$ is related with the complete mineralization of the benzene ring. The appearance of the peak at the lower wavelength region predicts that benzene ring like structures still exist even after 90 minutes degradation, although the solution is colourless.

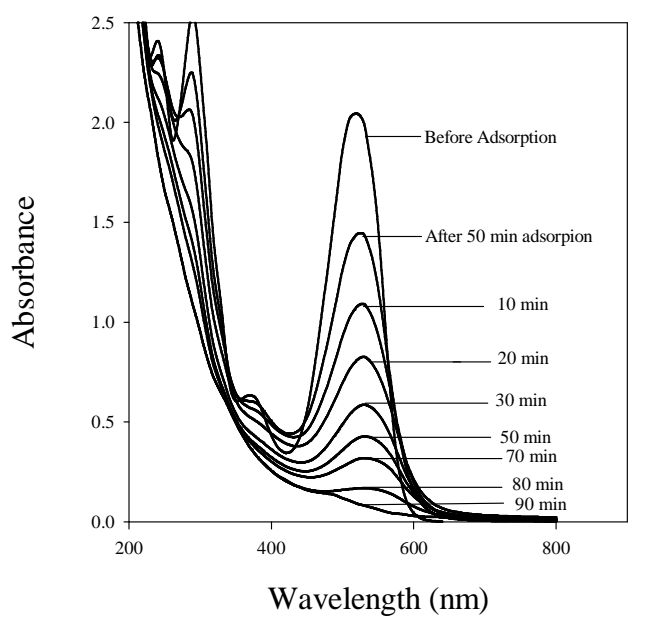

Fig. 2. Absorption spectra of $1.0 \times 10^{-4} \mathrm{M}$ RRR during adsorption and photodegradation by UV light in the presence of $0.10 \mathrm{~g} / 100.0$ $\mathrm{mL} \mathrm{MD-TiO}{ }_{2}$ suspension at different time intervals.

Characterization of the prepared sample by XRD

X-Ray Diffraction (XRD) phase analysis of the prepared $\mathrm{MD}-\mathrm{TiO}_{2}$ sample shows the characteristic peaks of MD$\mathrm{TiO}_{2}$ (Fig. 3). All the characteristics peaks are consistent with those reported by Macyk et $\mathrm{al}^{31}$ indicating the chemisorption of dichromate ion on the $\mathrm{TiO}_{2}$. The physical appearance of the coloured materials as well as the persistence of the colour even after sonication of these materials in presence of water indicates strong bonding between dichromate ions and $\mathrm{TiO}_{2}$. 


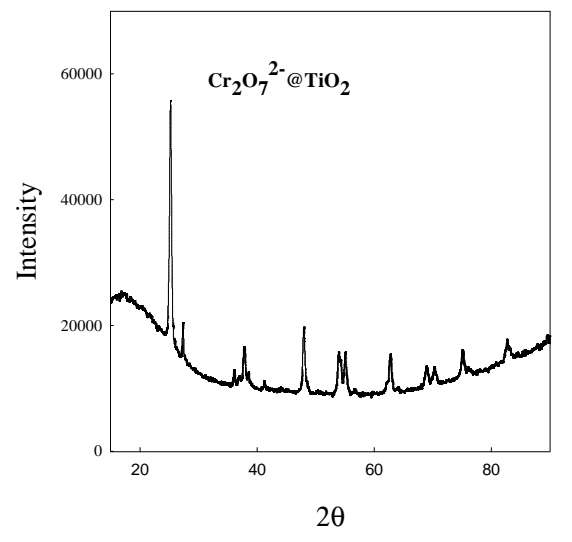

Fig. 3. XRD spectrum of $\mathrm{MD}-\mathrm{TiO}_{2}$ photocatalyst.

\section{Efficiency of the photocatalyst on removal of RRR}

The efficiency of $\mathrm{C}-\mathrm{TiO}_{2}, \mathrm{D}-\mathrm{TiO}_{2}$ and $\mathrm{MD}-\mathrm{TiO}_{2}$ on removal of RRR by both adsorption and photodegradation was investigated and the result is shown in Fig. 4. It is seen that RRR molecule does not adsorb on the $\mathrm{C}-\mathrm{TiO}_{2}$ while considerable extent of adsorption of RRR has occurred for $0.10 \mathrm{~g}$ of $\mathrm{D}-\mathrm{TiO}_{2}$ and $\mathrm{MD}-\mathrm{TiO}_{2}$. The initial rapid degradation for the latter two samples is due to adsorption together with photodegradation. In addition to these results, RRR does not undergo degradation in absence of any photocatalyst.

However, the dye molecules undergo photodegradation in presence of all forms of $\mathrm{TiO}_{2}$ under UV irradiation. Percent removal of RRR comprising adsorption and photodegradation was found $11 \%, 35 \%$ and $45 \%$ during 90 minutes of irradiation with $0.10 \mathrm{~g}$ of $\mathrm{C}-\mathrm{TiO}_{2}, \mathrm{D}-\mathrm{TiO}_{2}$ and $\mathrm{MD}-\mathrm{TiO}_{2}$ as photocatalyst respectively. The chemisorption of chromate (VI) species on the surface of $\mathrm{D}-\mathrm{TiO}_{2}$ photosensitizes $\mathrm{TiO}_{2}$, which enhances the photocatalytic activity of $\mathrm{MD}-\mathrm{TiO}_{2}$. Hence $\mathrm{MD}-\mathrm{TiO}_{2}$ becomes the most active photocatalyst ${ }^{31}$.

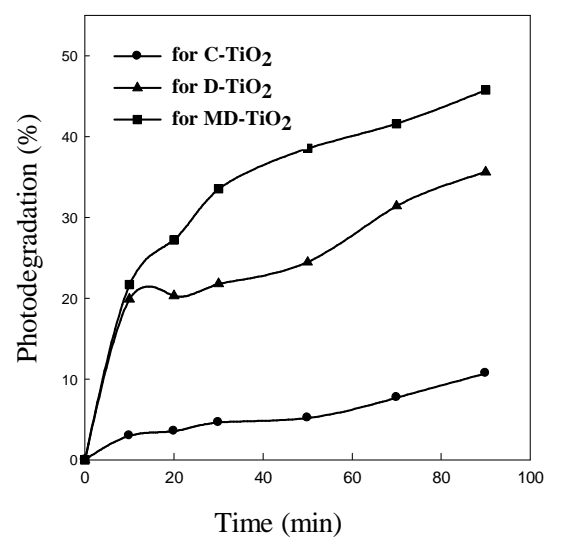

Fig. 4. Percentage of photodegradation of $1 \times 10^{-4} \mathrm{M}$ RRR solution in presence of $0.10 \mathrm{~g}$ of different types of $\mathrm{TiO}_{2}$ photocatalysts. Initial $\mathrm{pH}=5.0$.

\section{Effect of catalyst dosage on removal of $R R R$}

The amount of catalyst affects the rate as well as the extent of photocatalytic degradation. The effect of catalyst dosages was investigated by carrying out the experiments with different amount of $\mathrm{TiO}_{2}$ for each type catalyst used (Fig.5(a) and 5(b)). For C-TiO 2 the catalyst dosages were between $0.05 \mathrm{~g}$ and $1.6 \mathrm{~g} / 100 \mathrm{~mL}$ in $1.0 \times 10^{-4} \mathrm{M}$ RRR, but for $\mathrm{D}-\mathrm{TiO}_{2}$ and $\mathrm{MD}-\mathrm{TiO}_{2}$ these dosages were from $0.02 \mathrm{~g}$ to $0.14 \mathrm{~g} / 100 \mathrm{~mL}$ solution. It is seen that, as the concentration of catalyst increases, the percent degradation increases and reaches a maximum value, after that decreases with a further increase in the concentration. The optimum dosage is found to be different for different samples. The optimum dosages for $\mathrm{C}-\mathrm{TiO}_{2}, \mathrm{D}-\mathrm{TiO}_{2}$ and $\mathrm{MD}-\mathrm{TiO}_{2}$ are $1.20 \mathrm{~g}, 0.12 \mathrm{~g}$ and $0.10 \mathrm{~g}$ per $100 \mathrm{~mL}$ solution, respectively. Increase in the rate of degradation with increase in the amount of catalyst is due to availability of greater catalyst surface area for absorption of quanta and interaction of molecules in the reaction mixture with catalyst. As a result, the number of holes, hydroxyl radicals and super oxide anions $\left(\mathrm{O}_{2}^{-}\right)$are increased. These are principal oxidizing intermediate in advance oxidation process and increases the rate of degradation $^{32}$.

It is expected that after certain amount of $\mathrm{TiO}_{2}$, the surface area does not change anymore. Accordingly, the percentage degradation should show a constant value after a certain amount of $\mathrm{TiO}_{2}$. However,increased amount of $\mathrm{TiO}_{2}$ makes the suspension more cloudy. As a result, the light can't penetrate thus can't reach the bulk of the suspension. Thus, most particles of the $\mathrm{TiO}_{2}$ in the bulk remain ineffective in producing radicals for photodegradation. It is interesting to note that the optimum degradation capacity changes to lower dosage region with $\mathrm{D}-\mathrm{TiO}_{2}$ and $\mathrm{MD}-\mathrm{TiO}_{2}$. This phenomenon can be correlated with the smaller particle size of these two samples compared with those of the $\mathrm{C}-\mathrm{TiO}_{2}$.

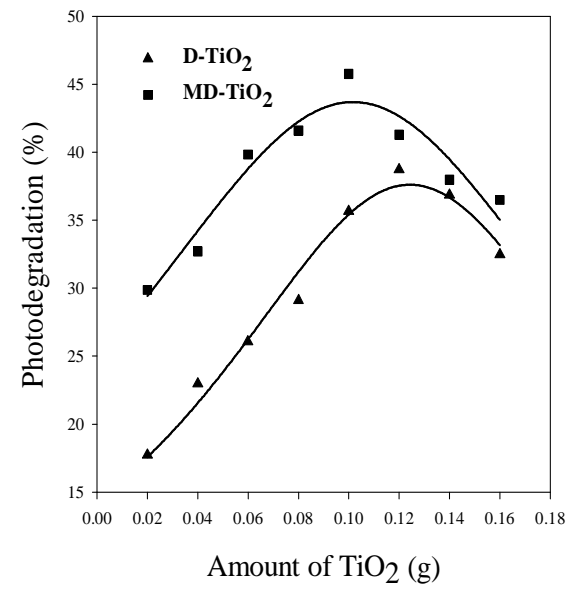

Fig. 5(a). Percent photodegradation of $1 \times 10^{-4} \mathrm{M}$ RRR solution in $90 \mathrm{~min}$ in presence of different amount of $\mathrm{D}-\mathrm{TiO}_{2}$ and $\mathrm{MD}-\mathrm{TiO}_{2}$ in suspension. 


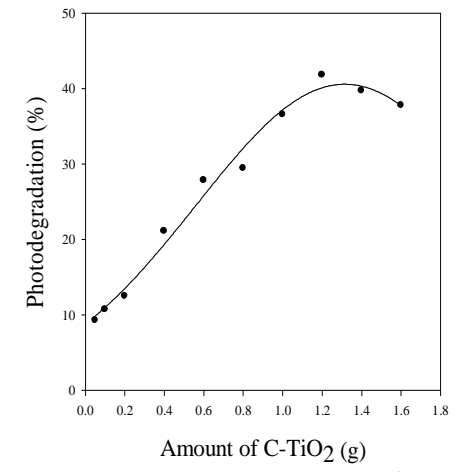

Fig. 5(b). Percent photodegradation of $1 \times 10^{-4} \mathrm{M}$ RRR solution in $90 \mathrm{~min}$ in presence of different amount of $\mathrm{C}^{-\mathrm{TiO}_{2}}$ in suspension.

\section{Effect of $p H$ on photodegradation of RRR}

$\mathrm{pH}$ value of the solution has an influence on the rate of photodegradation of some organic compounds $n$ photocatalytic processes ${ }^{33}$. To study the effect of $\mathrm{pH}$ on the photodegradation efficiency, experiments were carried out at various $\mathrm{pH}$ values, ranging from 2.0 to 6.0 at a constant dye concentration of $1 \times 10^{-4} \mathrm{M}$. The results show that the percent degradation is very high at high acidic $\mathrm{pH} 3.0$ for both $\mathrm{C}-\mathrm{TiO}_{2}$ and $\mathrm{MD}-\mathrm{TiO}_{2}$ and $\sim 4.0$ for D-TiO 2 (Fig.6). It is well established that upon hydration, the $\mathrm{TiO}_{2}$ surface develops hydroxyl groups, which can undergo a proton association or dissociation reaction ${ }^{33}$.

$$
\mathrm{TiOH}+\mathrm{H}^{+} \rightarrow \mathrm{Ti}(\mathrm{OH})_{2}{ }^{+} ; \text {at } \mathrm{pH}<\mathrm{pH}_{\mathrm{zpc}}
$$

The $\mathrm{pH}_{\mathrm{zpc}}$ of $\mathrm{TiO}_{2}$ is within 6 to 7. So in the acidic solution of $\mathrm{pH}<\mathrm{pH}_{\mathrm{zpc}}$. the surface of $\mathrm{TiO}_{2}$, is presumably positively charged. Since the dye has a negatively charged sulfate group, the acidic solution favors degradation of dye onto photocatalyst surface. The photogenerated electron transfer becomes easier from the bulk to the interface due to electrostatic attraction, which is probably due to close approach of the negatively charged dye to a positive oxide surface. Hence the photodegradation efficiency increases. At a $\mathrm{pH}$ lower than 3.0, the suspension of $\mathrm{TiO}_{2}$ is coagulated and settled down into the beaker. The net result is the lowering of the rate of degradation.

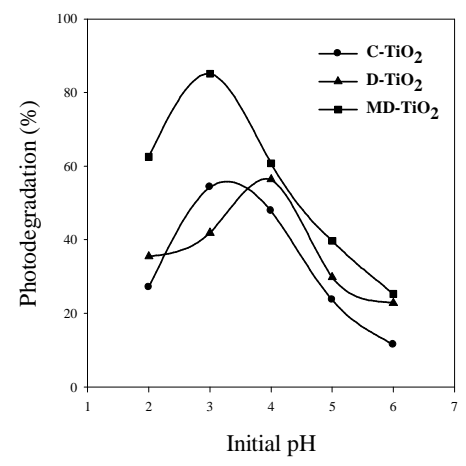

Fig. 6. Plots of percent photodegradation of RRR in 90 min against initial $\mathrm{pH}$ of the solution for different types of $\mathrm{TiO}_{2}$ photocatalysts. Amount of the catalysts are $\mathrm{C}-\mathrm{TiO}_{2}=1.20 \mathrm{~g} / 100 \mathrm{~mL}, \mathrm{D}-\mathrm{TiO}_{2}=$ $0.12 \mathrm{~g} / 100 \mathrm{~mL}, \mathrm{MD}^{-\mathrm{TiO}_{2}}=0.10 \mathrm{~g} / 100 \mathrm{~mL}$.

\section{Effect of initial concentration of RRR on photodegradation}

The photocatalytic degradation of RRR solution was carried out by varying the initial concentration of RRR from $0.5 \times$ $10^{-4} \mathrm{M}$ to $2.0 \times 10^{-4} \mathrm{M}$ in order to assess the appropriate concentration required for maximum degradation. For these experiments, $\mathrm{MD}-\mathrm{TiO}_{2}$ was used as the photocatalyst.

The results show that with the increase of initial concentration of RRR, the percentage of photodegradation decreases (Fig. 7). As the dye concentration is increased, the light can penetrate less on the surface of the catalyst because most of the light is absorbed by the dye. Moreover, the higher value of the denominator lowers the value of the percentage degradation ${ }^{34}$.

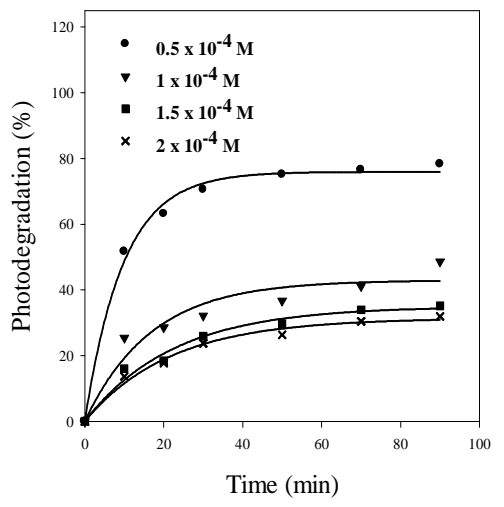

Fig. 7. Percent photodegradation of different concentrations of RRR solution with time. Amount of $\mathrm{MD}^{-\mathrm{TiO}_{2}}=0.10 \mathrm{~g} / 100 \mathrm{~mL}$. Initial $\mathrm{pH}=3.0$.

\section{Effect of light sources on photodegradation of RRR}

To study the effect of light sources on photodegradation of RRR several experiments were carried out in sunlight, artificial visible light and UV light (Fig. 8). The results show that percent photodegradation with $\mathrm{MD}-\mathrm{TiO}_{2}$ was found to be $85.1 \%, 54.5 \%$ and $95.9 \%$ under UV, artificial visible and sunlight, respectively under $90 \mathrm{~min}$ irradiation. Again, for $\mathrm{C}-\mathrm{TiO}_{2}$ photocatalyst, $54.3 \%, 24.6 \%$ and $52.3 \%$ photodegradation of RRR were found under UV, artificial visible and sunlight, respectively. Finally, for $\mathrm{D}-\mathrm{TiO}_{2}$ photocatalyst $41.9 \%, 42.3 \%$ and $59.9 \%$ photodegradation of RRR were found by UV, visible and sun light, respectively.

The degradation by the sun light is about $10.8 \%$ higher than the artificial UV and $41.4 \%$ higher than the artificial visible light after $90 \mathrm{~min}$ irradiation for $\mathrm{MD}-\mathrm{TiO}_{2}$. The intensity of the UV light source was measured previously which was $0.14 \mathrm{~mW} \mathrm{~cm}^{-2} \mathrm{~s}^{-1} .{ }^{35}$ Although the intensity of the sunlight was not measured, this value is higher than the value measured for $\mathrm{UV}^{\mathbf{3 6}}$. It is well known that the photocatalyst, $\mathrm{TiO}_{2}$ is a semiconductor having a band gap energy of $3.2 \mathrm{eV}$ which corresponds to $387 \mathrm{~nm}$ of thewavelength of the radiation. Thus, any light having wavelength less than $387 \mathrm{~nm}$ will be capable of producing electron-hole pairs and causes photodegradation. Visible light can cause photodegradation by different mechanism, where dye molecules become excited by absorbing the light photon. 
These excited molecules transfer electrons to the conduction band of $\mathrm{TiO}_{2}$. However, a higher rate of degradation by the sunlight than the artificial visible light could be related to the very high intensity of this light.

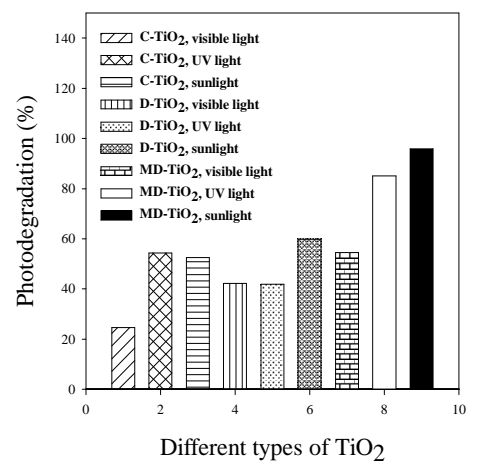

Fig. 8. Percent photodegradation of $1 \times 10^{-4} \mathrm{M}$ RRR solution in presence of $\mathrm{C}-\mathrm{TiO}_{2}$. D- $-\mathrm{TiO}_{2}$ and $\mathrm{MD}-\mathrm{TiO}_{2}$ under artificial visible, $\mathrm{UV}$ and sun light. Amount of catalysts are $\mathrm{C}-\mathrm{TiO}_{2}=1.20 \mathrm{~g} / 100$ $\mathrm{mL}, \mathrm{D}-\mathrm{TiO}_{2}=0.12 \mathrm{~g} / 100 \mathrm{~mL}, \mathrm{MD}-\mathrm{TiO}_{2}=0.10 \mathrm{~g} / 100 \mathrm{~mL}$. Intial optimum $\mathrm{pH}=3.0$ for $\mathrm{C}_{-} \mathrm{TiO}_{2}$ and $\mathrm{MD}^{-\mathrm{TiO}_{2}}$ and $\mathrm{pH}=4.0$ for $\mathrm{D}$ $\mathrm{TiO}_{2}$.

\section{Conclusion}

The effectiveness of different photocatalysts like commercial, C-TiO 2 , Degussa P25, D- $\mathrm{TiO}_{2}$ and prepared surface modified, $\mathrm{MD}-\mathrm{TiO}_{2}$ has been investigated for the photodegradation of a textile dye RRR. Among these three catalysts, $\mathrm{D}-\mathrm{TiO}_{2}$ shows better adsorption efficiency but $\mathrm{MD}-\mathrm{TiO}_{2}$ yields a net higher photocatalytic efficiency than the other two catalysts. The optimum concentration of $\mathrm{MD}-\mathrm{TiO}_{2}$ for the photodegradation of RRR was found to be $0.10 \mathrm{~g} / 100 \mathrm{~mL}$ whereas those of D$\mathrm{TiO}_{2}$ and $\mathrm{C}-\mathrm{TiO}_{2}$ were $0.12 \mathrm{~g} / 100 \mathrm{~mL}$ and $1.20 \mathrm{~g} / 100 \mathrm{~mL}$, respectively. Photodegradation decreases with the increase of initial concentration of RRR. Increased concentration of RRR might make the light difficult to penetrate the solution to reach the surface of the oxides to generate photoholes and electrons. Maximum photodegradation was found at $\mathrm{pH} 3.0$ for both $\mathrm{C}-\mathrm{TiO}_{2}$ and $\mathrm{MD}-\mathrm{TiO}_{2}$ but 4.0 for $\mathrm{D}-\mathrm{TiO}_{2}$. It has been observed that almost $96.0 \%$ of $1.0 \times 10^{-4} \mathrm{M}$ of RRR was photodegraded when irradiated 90 min under sunlight in the presence of $0.10 \mathrm{~g} / 100 \mathrm{~mL}$ of $\mathrm{MD}-\mathrm{TiO}_{2}$. Photodegradation was much higher in sunlight than in UV and visible light because of the greater intensity of light.

\section{Acknowledgement}

The authors are grateful to Dr. Tapas Debnath of the Department of Chemistry, Dhaka University for providing XRD data.

\section{References}

1. Reife, A. and H.S. Fremann, 1996. Environmental Chemistry of Dyes and Pigments, Wiley, New york,

2. Behnajady, M.A., N.Modirshahla, N. Daneshvarand and M. Rabbani, 2007. Photocatalytic degradation of an azo dye in a tubular continuous-flow photoreactor with immobilized $\mathrm{TiO}_{2}$ on glass plates. J. Chem. Eng. 127, 167-176.
3. Robinson, T., G. McMullan, R. Marchant and P. Nigam, 2001. Remediation of dyes in textile effluent: a critical review on current treatment technologies with a proposed alternative. Bioresour. Technol. 77, 247-255.

4. Habibi, M. H., A. Hassanzadeh and S. Mahdavi, 2005. The effect of operational parameters on the photocatalytic degradation of three textile azo dyes in aqueous $\mathrm{TiO}_{2}$ suspensions. J. Photochem. Photobiol. A Chem. 172, 89-96.

5. Bizani, E., K.Fytianos, I. Poulios and V. Tsiridis, 2006. Photocatalyticdecolorization and degradation of dye solutions and wastewaters in the presence of titanium dioxide. $J$. Hazard. Mater. 136, 85-94.

6. Jonstrup. M., 2011. Treatment of textile waste waters using combination of biological and Physico-chemical methods. $J$. Photochem. Photobiol. A: Chem, 291, 133-139.

7. Groff. K. A. Research Journal WPCE, 1991, 63, 459-460.

8. Lavkulich, L. M. and J. H. Wiens, 1970. Comparison of Organic Matter Destruction by Hydrogen Peroxide and Sodium Hypochlorite and Its Effect on Selected Mineral Constituents. Soil Sci. Soc. Am. J. 34, 755-758.

9. Chen, C., C. S. Lu and Y. C. Chung, 2006. Photocatalytic degradation of ethyl violet in aqueous solution mediated by $\mathrm{TiO}_{2}$ suspensions. J. Photochem. Photobiol. A: Chem, 181, 120-125.

10. Kyung, H., J. Lee and W. Choi, 2005. Simultaneous and Synergistic Conversion of Dyes and Heavy Metal Ions in Aqueous $\mathrm{TiO}_{2}$ Suspensions under Visible-Light Illumination. Environ. Sci. Technol. 39, 2376-2382.

11. Chen, X. Li, J. Zhao, H. Hidaka and N. Serpone, 2002. Effect of Transition Metal Ions on the $\mathrm{TiO}_{2}$-Assisted Photodegradation of Dyes under Visible Irradiation: A Probe for the Interfacial Electron Transfer Process and Reaction Mechanism. J. Phys. Chem. B, 106, 318-324.

12. Watanabe, N., S. Horikoshi, A. Kawasaki, H. Hidaka and N. Serpone, 2005. Formation of Refractory Ring-Expanded Triazine Intermediates during the Photocatalyzed Mineralization of the Endocrine Disruptor Amitrole and Related Triazole Derivatives at UV-Irradiated $\mathrm{TiO}_{2} / \mathrm{H}_{2} \mathrm{O}_{2}$ Interfaces. Environ. Sci. Technol., 39, 2320-2326.

13. Dimitrijevice, N. M., Z.V. Saponjic, B.M. Rabatic and T. Rajh, 2005. Assembly and Charge Transfer in Hybrid $\mathrm{TiO}_{2}$ Architectures Using Biotin-Avidin as a Connector. J Am Chem Soc. 127, 1344-1345.

14. Das, S., P.V. Kamat, S. Padmaja and S.A. Madison, 1999. Free radical induced oxidation of the azo dye Acid Yellow 9. J. Chem. Soc. Perkins Trans. 2, 1219-1224.

15. Yang, Y., D. T. Wyatt and M. Bahorsky, 1998. Decolorization of dyes using $\mathrm{UV} / \mathrm{H}_{2} \mathrm{O}_{2}$ photochemical oxidation. Textile Chem. Color. 30, 27-35.

16. Asahi, R., T. Morikawa, T. Ohwaki, K. Aoki and Y. Taga, 2001. Visible-Light Photocatalysis in Nitrogen-Doped Titanium Oxides. Science. 293, 269.

17. Morikawa, T., R. Asahi, T. Ohwaki, K. Aoki and Y. Taga, 2001. Band-Gap Narrowing of Titanium Dioxide by Nitrogen Doping. Jpn. J. Appl. Phys. 40, 561.

18. Sakthivel S. and H. Kisch, 2003. Photocatalytic and Photoelectrochemical Properties of Nitrogen-Doped Titanium Dioxide. Chem. Phys. Chem. 4, 487 
19. Lettmann C., K. Hildenbrand, H. Kisch, W. Macyk and W.F. Maier, 2001. Visible light photodegradation of 4chlorophenol with a coke-containing titanium dioxide photocatalyst. Appl. Catal. B: Environ. 32, 215.

20. Sakthivel S. and H. Kisch, 2003. Daylight Photocatalysis by Carbon-Modified Titanium Dioxide. Angew. Chem. Int. Ed. 42, 4908 .

21. Ohno T., T.Tsubota, M. Toyofuku and R. Inaba, 2004. Photocatalytic Activity of a $\mathrm{TiO}_{2}$ Photocatalyst Doped with $\mathrm{C}^{4+}$ and $\mathrm{S}^{4+}$ Ions Having a Rutile Phase Under Visible Light. Catal. Lett. 98, 255-258.

22. Zabek P., J. Eberl and H. Kisch, 2009. On the origin of visible light activity in carbon-modified titania. Photochem. Photobiol. Sci. 8, 264-269.

23. Luo H., T. Takata, Y. Lee, J. Zhao, K. Domen and Y. S. Yan, 2004. Photocatalytic Activity Enhancing for Titanium Dioxide by Co-doping with Bromine and Chlorine. Chem. Mater. 16, 846-49.

24. Hong X., Z. Wang, W. Cai, F. Lu, J. Zhang, Y. Yang, N. Ma and Y. Liu, 2005. Visible-Light-Activated Nanoparticle Photocatalyst of Iodine-Doped Titanium Dioxide. Chem. Mater. 17, 1548-52.

25. Rahman M. M., K. M. Krishna, T. Soga, T. Jimbo and M. Umeno, 1999. Optical properties and X-ray photoelectron spectroscopic study of pure and $\mathrm{Pb}$-doped $\mathrm{TiO}_{2}$ thin films. $J$. Phys. Chem. Solids. 60, 201-210.

26. Martin S. T., C. L. Morrison and M.R. Hoffmann, 1994. Photochemical Mechanism of Size-Quantized VanadiumDoped $\mathrm{TiO}_{2}$ Particles. J. Phys. Chem. 98, 13695-13704.

27. Radecka M., M. Wierzbicka, S. Komornicki and M. Rekas, 2004. Influence of $\mathrm{Cr}$ on photoelectrochemical properties of $\mathrm{TiO}_{2}$ thin films. Physica B. 348, 160-168.
28. Dvoranova D., V.Brezova, M. Mazur and M.A. Malati, 2002. Investigations of metal-doped titanium dioxide photocatalysts. Appl. Catal. B: Environ., 37, 91-105.

29. Zang L., W. Macyk, C. Lange, W.F. Maier, C. Antonius, D. Meissner and H. Kisch, 2000. Visible-light detoxification and charge generation by transition metal chloride modified titania. J. Chem. Eur. 6, 379.

30. Fu H., G. Lu and S. Li, 1998. Adsorption and photo-induced reduction of $\mathrm{Cr}(\mathrm{VI})$ ion in $\mathrm{Cr}(\mathrm{VI})-4 \mathrm{CP}$ (4-chlorophenol) aqueous system in the presence of $\mathrm{TiO}_{2}$ as photocatalyst. $J$. Photochem. Photobiol. A: Chem. 114, 81-88.

31. Macyk W., Z. Stasicka, J. Kuncewicz and P. Zabek, 2011. Visible light driven photocatalysis in chromate $(\mathrm{VI}) / \mathrm{TiO}_{2}$ systems-Improving stability of the photocatalyst. Catal. Today. 161, 78-83

32. Meena R.C., R. B. Pachwarya, V. K. Meena and S. Arya 2009. Degradation of textile dyes Ponceau-S and Sudan IV using recently developed photocatalyst, Immobilized Resin Dowex-11. American J. Env. Sci. 5, 444-450.

33. Mijin D., J. Radivojevic and P. Jovanckovic, 2012. A study of the photocatalytic degradation of textile dye CI basic yellow 28 in water using a $\mathrm{P} 160 \mathrm{TiO}_{2}$ - based catalyst.J. Serb. Chem. Soc., 77, 1747-57.

34. Epling G. A. and C. Lin, 2002. Photoassisted bleaching of dyes utilizing $\mathrm{TiO}_{2}$ and visible light. Chemosphere., 46, 561-70.

35. Mahmood A. J., M. S. Islam and M. M. Hossain, 2003. ZnO Mediated Degradation of Brilliant Orange by Visible Light. $J$. Bangladesh Chem. Soc. 16, 36-43.

36. http://en.wikipedia.org/wiki/Sunlight. 